UDK 871.61

Leon Stefanija

Filozofska fakulteta Univerze v Ljubljani

Faculty of Arts, University of Ljubljana

\title{
Slišano, predstavljeno in razbrano Razmislek o obsegu področja analize glasbenega stavka
}

\section{Heard, Presented, Understood Reflecting Upon the Boundaries of Music Analysis}

Ključne besede: analiza glasbenega stavka, teorija glasbe, semiologija glasbe, Claude LéviStrauss

\section{Povzetek}

Izhajajoč iz pogosto navajane domneve o "nelagodnem" položaju analize glasbenega stavka $\mathrm{v}$ sodobni muzikologiji, avtor v sestavku pretresa nekatere osrednje značilnosti področja analize sestavek v štirih poglavjih. Prvo poglavje zadeva oblikoslovje, drugo razmejitve analitičnih ravni, tretje konkreten primer analitičnega prikaza glasbe C. Lévi-Straussa, četrti pa prinaša komentar o vlogi analize glasbe v muzikologiji kot analize glasbenega jezika.
Keywords: music analysis, theory of music, semiology of music, Claude Lévi-Strauss

\section{SUMMARY}

Considering the frequently stated assumption that the current position of (and within) the field of music analysis is "uneasy", the author, through four focuses, discusses some vital characteristics of music analysis. Firstly, he speaks about morfology ("Formenlehre") in music, secondly, about the demarcation of analytical levels, thirdly, he comments on C. Lévi-Strauss's concrete example of analysis, and finally he concludes with a remark on music analysis as an activity of analysing the language of music.

Sestavek vsebinsko sodi na področje teorije analize glasbenega stavka. Gre za razmislek o problemskem obsegu muzikološke veje, katere izhodišče je razčlenjevanje glasbenega stavka.

Izhajam iz pogosto izrekanega stališča o nelagodnem položaju analize glasbenega stavka znotraj sodobne muzikologije. To nelagodje je mogoče, s potrebno mero poenostavljanja, nakazati ob zgovorno naslovljenem in odmevnem eseju How We Got into Analysis, and How to Get Out Josepha Kermana. Kermanova zahteva po iskanju drugih "estetskih vrednot mimo organicizma" $v$ analizi in ne po "izhodu iz analize"1 se je izkazala za utemeljeno.

Pomislimo samo na analitične prispevke t.i. "New", "Critical" ali "Narrative" musico$\log y$, semiološko in antropološko naravnane glasbenoanalitične nastavke, ki so spodbu-

\footnotetext{
${ }^{1} \mathrm{~V}$ izvirniku se poanta glasi takole: "What is important is to find ways of dealing responsibly with other kinds of aesthetic value in music besides organicism. I do not really think we need to get out of analysis, then, only out from under." (Kerman 1980: 331).
} 
dili procese (po Jimu Samsonu) "relokacije" (Samson 22001: 52) analize zaradi sodobnih "izzivov do institucij" (prav tam) in njihovih ustaljenih navad. Toda izrazito razsvetljensko naziranje, ki "relokacije" analize izvaja v imenu "renewal and discovery within the larger discipline of musicology" (prav tam), posledično seveda terja razmislek o "the larger picture" (prav tam: 54), tudi muzikologije. To verižno pomikanje pričakovanega odgovora iz ožjega področja glasbene analize (razčlenjevanja glasbenega stavka) na širše področje analize glasbe, ki bi ga lahko strnili z mislijo o pomikanju analitičnega obzorja "iz teksta na kontekst", nakazuje kompleksno, nelagodno pozicijo področja analize glasbe. Če so namreč v šestdesetih in sedemdesetih letih 20. stoletja mnogi pozdravili okrepljen muzikološki interes za analizo glasbe kot ozaveščenost dotlej preveč zanemarjane panoge $\mathrm{v}$ muzikologiji, je področje konec osemdesetih postalo izjemno obširno. Vsebuje tako teoretske in metodološke sklope, razvejan analitični interes po analizi vedno širšega repertorija in $\mathrm{z}$ njim povezanih členov glasbene prakse tako evropske köt zunajevropske muzike - v enaki meri t.i. resne kot zabavne - in (zlasti na anglosaksonskem govornem področju) zanimanje za analizo izvajalske prakse. Brez vpletanja v sociološke razsežnosti tega nelagodnega statusa analize glasbe je torej mogoče reči, da je analiza glasbenega stavka muzikološka disciplina, katere področje se spričo problematiziranja doslej predlaganih analitičnih metod - eden vodilnih angleških analitikov N. Cook jim odreka vsakršno "resnično znanstveno vrednost" (Cook 1994) - še ni izoblikovalo in ga že ni več. Vezano je na preveč konkretnih "interesnih skupin" (glasbenih, poslušalskih in ne nazadnje muzikoloških tradicij), da bi jo mogli opredeliti s skupno definicijo.

\section{Slišano in predstavljeno I: prispevek oblikoslovja}

Terminološke opredelitve, ki tvorijo zgodovino oblikoslovja do A. B. Marxa, razkrivajo proces sistemizacije oblikovnih tvorb, ki temelji na dveh spoznavnih področjih: na nauku o harmoniji, ki ga je J.-Ph. Rameau kodificiral v Traite de l'harmonie (1722) s pretenzijo po "znanosti", in na "rhythmopoeii" ali nauku o "urejevanju taktov" ("Tactordnung”, kakršnega je podal Joseph Riepel v svojem kompozicijskem priročniku Anfangsgründe zur musikalischen Setzkunst (1752), ki je izrecno pedagoško naravnan.

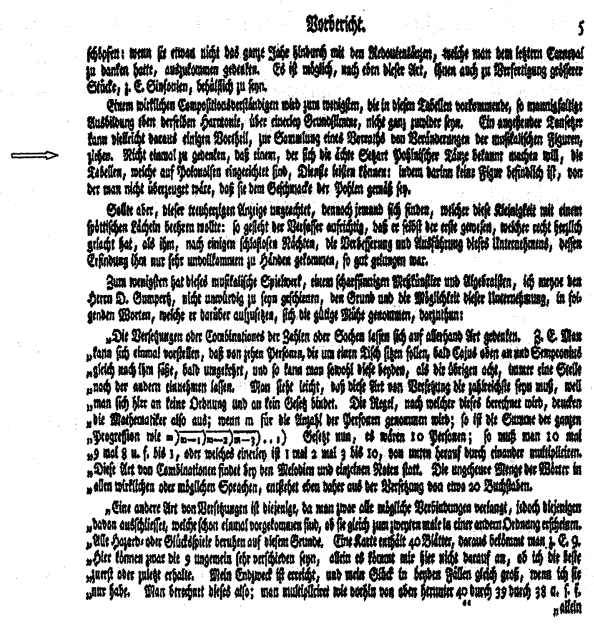

\footnotetext{
2 "A B C für diejenigen / welche verlangen die Setzeregeln einzusehen und nicht für die / so Gesetze vorzuschreiben wissen." (Riepel 1752: Einleitung, 2.)
} 
Dejstvo, da Rieplov kompozicijski nauk - "A B C za tiste, ki želijo dobiti vpogled v pravila tvorjenja glasbenega stavka, in ne za tiste, ki jih znajo predpisovati" - ${ }^{2}$ izhaja iz kadenčne zveze T-D-T kot osnovnega, hierarhično prvotnega in funkcijsko glavnega vzorca glasbenega stavka, dopušča nasloviti vprašanje oblikovnosti vsaj na tri ravni glasbenega stavka: kompozicijsko, estetsko in idejno. Prvič, sredi 18. stoletja razširjeno prepričanje, da "menuet po zgradbi ni nič drugačen od koncerta, arije ali simfonije,"3 kaže po kompozicijski plati razumeti kot posledico kompozicijskega nauka, katerega osnova je pri Matthesonu (1739) nakazana, pri Rieplu (1752) nadrobno komentirana in pri Kirnbergerju (1757) sistematično podana mehanska "komponiranje s kockami" (t.i. "Würfelkomposition"). Enotaktne oblikovne vzorce, iz katerih lahko "sestavlja" menuete, poloneze in trie vsak, ki zna metati kocko oziroma si poljubno izmisliti sosledje števil v danem okviru (6/12) in brati note, Kirnberger sugerira tudi kot "zbirko zaloge predrugačevanja glasbenih figur," ki prinaša praktično komajda izčrpne možnosti variiranja kombinacij med posameznimi harmonsko-melodičnimi figurami.

Za kombinatoriko gradnje glasbenega stavka, ki jo prinaša tovrstni "mehanizem" ("Spielwerk") nizanja melodično figuriranih harmonskih zvez, je značilno, da jo vrsta avtorjev od J. Matthesona naprej opisuje $z$ besedjem, ki izhaja iz jezikoslovno-retorične tradicije, vendar skuša slediti postulatom estetskega formalizma. Na primer: v kompozicijskih učbenikih J. Riepla, kjer je razvidno, da avtor skuša diferencirati osnovne pojme "Absatz", "Einsatz" in "Theil", ${ }^{4}$ toda namesto sistematične ureditve razmerij med njimi ostaja Rieplov kompozicijski priročnik pri izčrpni obravnavi "abstraktnejše" logike povezovanja številčno različno dolgih zvez od enega do devet taktov: "Einer" (enotaktje), "Zweyer" (dvotaktje), "Dreyer", "Vierer", "Fünfter", "Sechser", "Achter" in "Neunter". Temeljno estetsko vrednost posameznih oblikovnih členov - in "red taktov," poudarja Riepel, je "glavni del glasbene kompozicije vseh skladb" - vidi v vsebinsko "raztegljivi" oblikoslovni kategoriji: "soodvisnost" (Zusammenhang). Tudi pri menuetu se namreč "ein ganzer Zusammenhang erfordert wird, als zu einem Concert, einer Arie, Simpfonie, u.s.f." (Riepel 1752: 2). Kajti soodvisnost oblikotvornih členov - rezultat harmonske hierarhije in skladateljevega izbrušenega "okusa" pri vodenju melodike - je za skladbo enako potrebna kot zaokroženost celote s sodimi takti, ki da "jih je naša natura tako vsadila, da se zdi težko (z zadovoljstvom) poslušati kak drug red" (Riepel 1752: 23). Riepel torej očitno nadomesti ideal "zvočnega govora" ali "tonskega jezika" (Mattheson: "Klangrede", "Tonsprache") in z njim povezane vsebinsko-retorične analogije s podmeno organicizma.

Rieplove teoretske iztočnice so, kot je verjetno znano, ključne za "predzgodovino" oblikoslovja kot posebne glasbenoteoretske discipline, kakršno je izoblikoval A. B. Marx. Ključne so kot referenčna točka, ob kateri je razvidna vsebinska premena, značilna za

\footnotetext{
${ }^{3}$ V vlogi učitelja Riepel poudari: "Da aber ein Menuet, der Ausführung nach, nichts anders ist als ein Concert, eine Arie, oder Simpfonie; welches du [,Discantista“] in etlichen Tagen ganz klar sehen wirst; also wollen wir immer ganz klein und verächtlich anfangen, um nur bloß was grösseres und lobwürdigeres daraus zu erlangen.” (Prav tam, 1.)

" Absatz (odstavek), ki ga ponazori (1752) z dvotaktom (3/4: c"-g'-b'/a'/d"a'c"/h); po Rieplu (Grundregeln zur Tonordnung insgemein, 1755) obstajata dve vrsti: Grundabsatz, ki se konča s kadenco na toniki, in Aenderungabsatz, ki se konča na dominanti (36ff); Quint-Aenderungs-Absatz (64) se nanaša na dvotakt pri modulaciji v dominanto. Einsatz: členjeni (razširjeni ali sestavljeni) Absatz (1755, 52ff).

Theil: odsek iz določenega stavka, zaključen s kadenco, do katerega vodi delna ali celovita ponovitev (Wiederholung), ponovitev kadence (Verdoppelung), zunanja razširitev (Ausdähnung), skrajšanje (Verkürzung), vstavek (Einschiebel) znotraj posamezne metrične enote ipd.

${ }^{5}$ Riepel 1752, 3: "Es ist ja dieses, nämlich die Tactordnung vollkommen innen zu haben, unter andern ein Haupttheil der Composition aller musicalischen Compositionen; und werden weder die Fugenarten gänzlich davon ausgeschlossen."
} 
pojem "glasbena logika" (prim. Dahlhaus 1979: 105-117) namreč premena, po kateri se je pojem v 18. stoletju nanašal predvsem na harmonsko zasnovo "ritma", kot ga pojmuje še A. Reicha - torej "ritma" kot ritmično-harmonsko-melodičnega člena (dvo-, tri-, šes-, sedemtaktja ali stavka) -, v 19. stoletju pa na motivično-tematsko mrežo povezav v skladbi, ki jih je Reicha poimenoval "dessin" (v Czernyjevem prevodu Reichovega traktata: "Umriss"). Premena, kot kaže vzporednica med Reichovo in Marxovo opredelitvijo motiva:

\section{A. Reicha (1814: 365)}

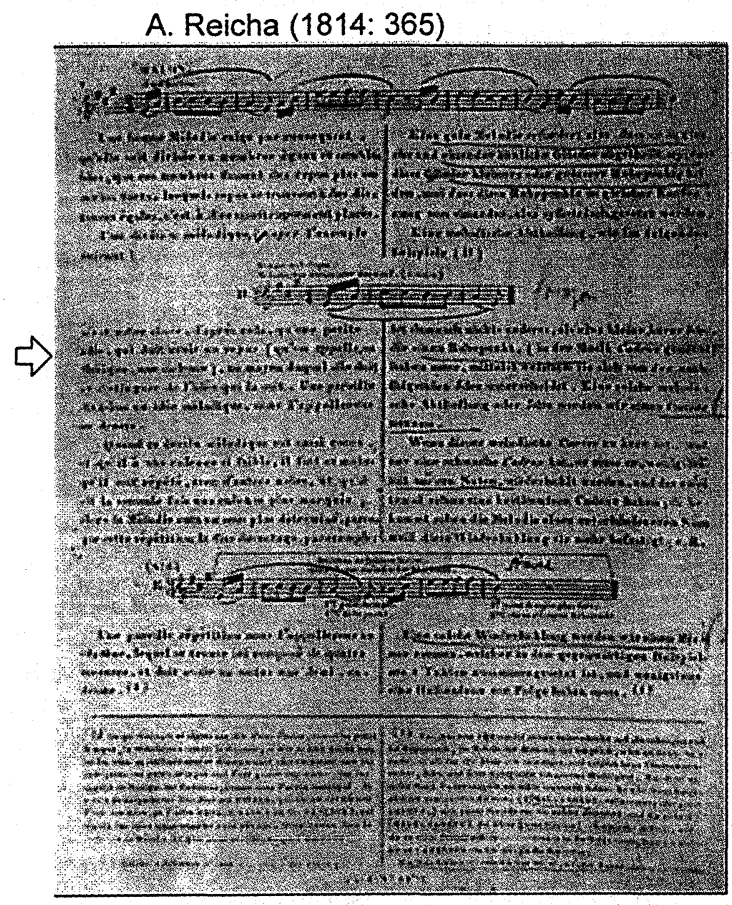

\section{A. B. Marx (1837: 32)}

\section{A. B. Marx (1837: 32)}

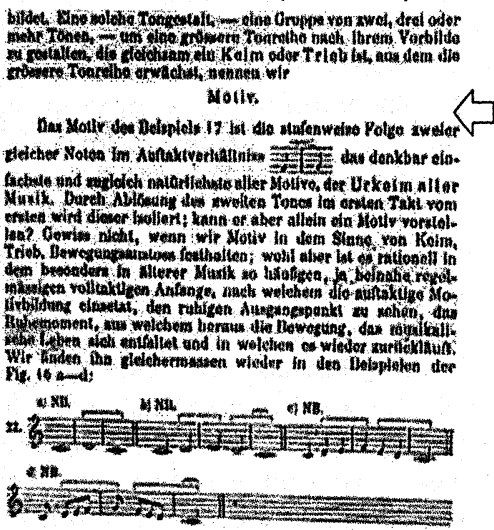

se nanaša na različno estetsko vlogo motivičnega jedra. Če pri Reichi "melodični odsek [Abtheilung] ni nič drugega kakor majhna, kratka ideja, ki mora imeti točko umiritve [...] s katero se ločuje od naslednje ideje," je za Marxa motiv "praklica [Urkeim] glasbe". Razlika med Reichovim "obrisom" (Dessin, Umriss) in Marxovim motivom torej ni v funkciji, ki jo imata pri vzpostavljanju soodvisnosti celote, temveč v estetski vrednosti, "teži", ki se jima pripisuje: "obris" je eden med mnogimi, estetsko zamenljiv in ciljno opredeljen glede na kontekst, "motiv" pa je, nasprotno, nezamenljivo estetsko merilo, ki določa in na katerega je tudi treba navezovati vsako nadaljnjo tonsko tvorbo.

Če je za Rieplov "nauk o ritmu" osrednjega pomena pojem soodvisnosti (Zusammenhang), je za oblikoslovne orise, ki vodijo k oblikoslovju A. B. Marxa ${ }^{6}$ in mu sledijo, ključna idejna podmena: organicizem. Zanjo oziroma za pojem organskega - jasno poudarjena ali potihem vključena pojmovna stalnica pedagoških priročnikov o glasbenih oblikah do danes - je značilno, da sta "zmogla združiti obe področji, [kompozicijsko-

${ }^{6}$ Ob H. Ch. Kochu zlasti Jérôme-Joseph de Momigny (Cours complet d'harmonie et de composition I-III: 1803, 1805, 1806). 
]tehnično in estetsko" (Schmidt 1990: 45). Organicizem torej združuje pri Rieplu nakazano, pri H. Ch. Kochu? pa vsaj načelno jasno razmejena pola "zunanjega" ("mehanskega") in "notranjega ustroja" glasbenega stavka, in briše tudi eno osrednjih ločnic v zgodovini estetike, ločnico med "formo" in "vsebino".

Po analogiji z razliko med muzikološkim raziskovanjem glasbenih oblik, kar Marx strne s pojmom "umetniške oblike" (Kunstform), in kompozicijsko teorijo oblikovanja, ki je za Marxa nauk o "bistvu umetniških oblik" in jo je kodificiral v novi disciplini, ki jo je poimenoval oblikoslovje (Formenlehre), ${ }^{8}$ je prepletanje kompozicijske in estetske (recepcijske) ravni "glasbenih organizmov" terjalo nenehno širitev opisnih vzporednic, ki jih je pojem organskega dopuščal v 19. in na prelomu v 20. stoletje. (Prim. Thaler 1984: 13-54.) Možnost širitve organicističnih prispodob, kot je opozoril Schmidt ob Marxovem opisu "principa Bachove kompozicije", ki sledi analizi predelave korala Christ, unser Herr, zum Jordan kam, se je razkrila na ravni perspektive opazovanja "organskega naravnega razvijanja" ("organische Naturentwicklung"). Natančneje, razkrila se je na spoznavni ravni, pri razlikovanju med nastalim (entstandene) in narejenim (gemachte), kar Schmidt označi kot "umetnostnoteoretski paradoks" (Schmidt 1990: 236). Ta je v učbenikih analize pogost $\mathrm{v}$ obliki opozorila, da je treba razlikovati med subjektivnimi domnevami in objektivnimi dejstvi in ga kaže razumeti kot enega osrednjih razlogov, da različice organicističnega pojmovanja glasbene celote tako rekoč silijo iz koncepta, znotraj katerega so nastale. "Kajti analogija se neopazno pretvori v postulat," poudarja Lotte Thaler, "v kolikor se zabriše meja med [organskim kot] nazorskim modelom in [potezami] opazovanim predmetom; tako morejo država, družba, jezik in umetnost v enaki meri postati živi, naravni organizmi." (Thaler 1984: 7.)

Kot kompozicijski pojem, ključen za oblikoslovje vsaj od A. B. Marxa naprej, se torej organicizem nanaša na razmerja med posameznostmi glasbenega stavka. Kot estetski pojem pa organicizem prinaša $\mathrm{v}$ razmislek recepcijske korelate, po katerih se zgradba glasbenega stavka ne razkriva kot avtonomna, temveč semantično heteronomna oblika človekovega izraza. Obe plati je A. B. Marx skušal zediniti v oblikoslovju, novem nauku, ki bi, zasnovan na predočbi o organski glasbeni celoti, presegel dotedanje razmejevanje kompozicijskega nauka na posamezne poddiscipline (harmonijo, melodiko, ritem). (Prim. Marx 1837: Einleitung, 7 in dalje.) Tako je obenem omogočil, da se ob značilnostih "narejenega", vselej objektivno avtorske in zgodovinsko oprijemljive, razkrijejo in razvijajo vselej subjektivne in "splošne" in ne samo na glasbo zamejene recepcijske poteze "nastalega". In kaj prinaša ta vsebinska "prepustnost" organicizma, ki izvira iz oblikoslovja in se je kasneje razvijala v sodobn(ejš)ih analitičnih predlogah (na primer LaRue ${ }_{2} 1992$; Berry ${ }_{2} 1987$; Lerdahl / Jackendoff 1983) za razkrivanje strukturno-oblikovnih značilnosti glasbenega stavka?

\footnotetext{
7 Heinrich Christoph Koch: "Raznolikost delov, ki tvorijo skladbo, je mogoče obravnavati tako po njihovi notranjem kakor tudi zunanjem ustroju [innere/äusserliche Beschaffenheit]. Če se deli obravnavajo s stališča notranje kakovosti [Beschaffenheit] ali po tem, kako so po sebi in za sebe lepi ter kako raznoliko se držijo med seboj, potem je genij, podprt $z$ okusom, tisti, ki te dele iznajdeva in izbira [...]. Če pa raznolikost delov obravnavamo s stališča zunanjega ustroja [Beschaffenheit], jih moremo opazovati 1) glede različnosti njihovih figur, 2) različnosti njihovih zaključkov in 3) različnosti modulacij, to je glede vodenja glasov." (Koch 1782: 12-13.)

${ }^{8}$ A. B. Marx je poudaril, "da lahko obstaja več ali mnogo umetniških oblik," ki jih je treba razumeti kot "utelešenje glavnih potez množice posameznih umetniških del," da pa je "bistvo umetniških oblik" naloga oblikoslovja. (Marx 1838: 5.) Podobno razliko navajata denimo C. Kühn in Lothar Schmidt. Medtem ko Kühn razume nauk o oblikah (Formenlehre) kot področje muzikološkega raziskovanja, ki skuša "ob stvarnih prikazati tudi zgodovinske soodvisnosti" Za Kühna, pojmuje oblikoslovje (Formenlehre) kot skupek ponazoritev "tipov in modelov". (Kühn ${ }^{31992: ~ 8 .) ~ S c h m i d t ~ p r i ~ a n a l i z i ~}$ Marxovega učbenika kompozicije opozori na razliko med "oblikoslovjem" in naukom o "umetniških oblikah" s tem, da spomni na tudi danes znano razliko v nemški muzikologiji med "Formenlehre" in "Formtheorie". (Schmidt 1990: 190.)
} 


\section{Slišano in predstavljeno II: teoretske opore}

Ni vprašljivo, da je analiza glasbenega stavka orodje razumevanja glasbenih pojavov, orodje, ki skuša razkriti "vsebino" glasbenih del. Tako se vprašanja o analizi glasbenega stavka začnejo zapletati na točki, ko je treba slišano vsebino predstaviti.

Vreteno niti različnih "naracij" v grobem začne ločevati predstavitve slišanega s tako elementarnimi razmejitvami, kot jih ponujajo denimo Bojan Bujić, Hans Heinrich Eggebrecht, Nicholas Cook ali Kurt Hübner. Bujić govori o "our continuing wavering between two modes of listening" (Bujić 1997: 22): o "dveh ravneh razumevanja glasbe", namreč (1) zasledovanju povezav med posameznostmi znotraj glasbene celote in (2) izpostavljanju ali "capturing some telling detail", kateremu "se pripiše določena vrednost" (prav tam: 19). V drugi preobleki, neodvisno drug od drugega, govorita o enaki dvojnosti slišanja glasbenega tudi $\mathrm{H}$. H. Eggebrecht in N. Cook kot o razliki med estetskem (ästhetisches) in spoznavnem razumevanju (erkennendes Verstehen) (Eggebrecht 1995) oziroma glasbenem (musical) in glasboslovnem poslušanju (musicological listening) (Cook 1992: 152 in dalje). Filozof K. Hübner to razliko med "estetskim" in "družboslovnim" pojmom nakaže kot razliko med kognitivnim in konotativnim slišanjem glasbenega stavka (Hübner:1994: 26-38).

Omenjeni avtorji se strinjajo, da podanih opozicij med seboj ne kaže ostro ločevati, temveč da jih je treba razumeti kot med seboj dopolnjujoči se ravni poslušalčevega odnosa do glasbe: po eni plati glasba kot fiziološki dražljaj, po drugi glasba kot "kontekstualizirajoči" (Bujić), "spoznavni" pojav (Eggebrecht in Cook), ki ima "simbolizirajoče" poteze, poteze "jezikovnosti".

\section{Slišano in predstavljeno III: razmejitev povezanega ob glasboslovnem pogledu Claudea Lévi-Straussa}

Misel o glasbi Lévi-Straussa se zdi na tem mestu ustrezna zato, ker v prečiščeni obliki razkriva problematiko, nakazano pri zgoraj omenjenih avtorjih in $v$ drugačnih oblikah prisotno $v$ večini glasbenoanalitičnih raziskavah.

Kot je znano, je bil Lévi-Strauss prepričan, da je mit "jezik, ki funkcionira na posebej visoki ravni". Podobno kot je videl v mitu "logični model, ki omogoča preseči kontradikcije," je videl tudi v glasbi - izhajajoč iz antropološko razumljenega vprašanja o glasbi kot jeziku, torej o glasbi kot svojevrstnem jeziku simbolov, ki ga kaže raziskovati po načelih teorije izmenjave (exchange theory) - določene sorodnosti z jezikom.

Čeprav je pogosto posvečal pozornost glasbi, je nemara najbolj jasno strnil svoj pogled na glasbo kot jezik v zadnjem iz niza intervjujev $\mathrm{z}$ naslovom Mythos und Bedeutung Bibliothek (Lévi-Strauss 1995: 65-79). Tu je poudaril dve vrsti povezav med mitom oziroma jezikom in glasbo: strukturno sorodnost in vsebinsko-funkcijsko kontigviteto (stičnost).

Strukturne vzporednice med mitom, jezikom in glasbo iz omenjenega pogovora je mogoče strniti z naslednjo preglednico:

\begin{tabular}{|l|l|l|}
\hline MIT & JEZIK & GLASBA \\
\hline$/ / /$ & fonem & sonem (tonem) \\
\hline beseda & beseda & $/ / /$ \\
\hline stavek & stavek & stavek ("melodija") \\
\hline
\end{tabular}


Tezi o strukturni sorodnosti glasbe in jezika, za katero je bržkone mogoče slutiti bogato zahodnjaško teoretsko tradicijo iskanja povezav med glasbenim stavkom in jezikom, sledi Lévi-Straussova teza o kontigviteti, po kateri naj bi glasba v 17., zlasti pa 18. stoletju, prevzela družbeno vlogo mita. Straussova teza o kontigviteti je intrigantna. Deloma je sprejemljiva, saj je glasba do 19. stol. postala tako rekoč vzor umetnosti. Vendar Strauss ne ponuja dovolj oprijemljivih argumentov: najde možnost utemeljitve (mit izpodriva razsvetljenski um), ne navaja pa razlogov (zakaj bi glasba prevzela funkcijo mita, saj ga kot neobhodni del kulturnih ritualov skozi zgodovino nikoli ni izgubila): manjka torej del argumentacije. Njegovi glavni argumenti se iztečejo v naslednji primerjavi semantičnosti glasbene oblike in strukture, ki je značilna za mit:

"Pozornost vzbuja denimo to, da fuga, ki je v Bachovem času dobila svojo ustaljeno obliko, zvesto ponavlja potek mitov $z$ dvema nastopajočima osebama ali dvema skupinama oseb. Poenostavimo in si predstavljajmo, da je prva dobra, druga zlobna. Pripoved, ki jo predstavlja mit, narekuje, da ena skupina poskuša ubežati drugi in se pred njo zavarovati; eno skupino torej lovi druga skupina, pri čemer enkrat skupina A dohiti skupino B, drugič skupina B lahko pobegne - popolnoma enako kot pri fugi. V francoščini to imenujemo le sujet et la réponse. Antiteza ali antifonija se razteza skozi celotno zgodbo, dokler se obe skupini skorajda popolnoma ne pomešata in prepleteta - to ustreza stretti fuge. Sledi sklepna razrešitev ali sklepni višek konflikta $v$ združitvi obeh principov, ki sta si bila v mitu vseskozi med seboj nasprotna. Lahko bi šlo za konflikt med višjimi in nižjimi silami, med nebesi in zemljo, med soncem in podzemeljskimi silami ali kaj podobnega. Glede na strukturo je mitična razrešitev $v$ združitvi močno podobna akordom, ki zaključujejo in sklenejo skladbo, kajti tudi sklepni akordi predstavljajo združitev skrajnosti, ki se v tem primeru spojijo. Povrh pa je mogoče pokazati, da obstajajo miti ali skupine mitov, katerih ustroj je enak zgradbi sonate ali simfonije, rondoja, tokate ali kaki drugi obliki izmed tistih mnogih, ki jih glasba ni ravno odkrila, temveč si jih je nezavedno izposodila pri mitu."

Lévi-Strauss očitno odreka "avtonomnost" celo oblikam, ki sodijo med paradigme (sicer problematično poimenovane in pogosto poenostavljeno tolmačene \{ prim. Tadday 1999 \}) "avtonomne", "absolutne" glasbe (fuga, sonata, tokata itn.). Po univerzalističnem načelu primerjane glasbene oblike $z$ oblikami mitov izgubijo izvirno ekskluzivnost. Glasbena oblikovnost ni le glasbena. Lahko je mitska, arhitekturna, slikarska, torej simbolna $\mathrm{v}$ širšem pomenu. (Lévi-Strauss $\mathrm{s}$ tem dodatno oslabi tezo o kontigviteti, čeprav le-ta še vedno ostaja smiselna in v določeni meri tudi nevprašljiva, saj se nanaša na glasbo, ki tvorijo srčiko glasbene tradicije Zahoda in pojma glasbe kot vzvišene dejavnosti človekovega duha.)

Zakaj je Lévi-Straussova misel o glasbi pomembna pri obravnavi mesta analize glasbenega stavka? Omeniti je treba vsaj dva razloga.

Prvič. Njegovo vztrajanje na identični oblikovni semantiki med mitom in glasbo 17.19. stoletja je kamenček v mozaiku široko uveljavljenega prepričanja o glasbi Zahoda, namreč o glasbi kot skupku glasbenih oblik in kompozicijskih vzorcev, ki - tako kot mit - vsebujejo določeno "elementarno, toda nikakor ne enostavno funkcijo", kot poudarja Jens Brockmeier (Brockmeier 1999: 178).

Drugič. Na podlagi simbolnih vzporednic lahko govorimo le o določeni elementarnosti glasbenega jezika. Ko Lévi-Strauss o glasbi govori kot o simbolnem mediju, ki zmore "sprejemati" in "opuščati" različne funkcije, strukturno sorodnost jezika, glasbe in mita prenese iz spoznavoslovnega na družboslovno raven: "oblike in strukture umetnosti tako raznoliko prekrite in medseboj razvejane kakor mitske" (prav tam 179). Tako je 
elementarna sorodnost glasbenih in ne-glasbenih oblik navidez šivankino uho, skozi katerega pa je mogoče potegniti cel šop niti povezav med mitom in glasbo - pa ne samo med njima, temveč tudi med glasbo in jezikom, glasbo in upodabljajočo oz. plastično umetnostjo, duševnimi ali pa naravnimi procesi. (Nemara odtod izvira Lévi-Straussova previdnost navajanja razlogov kontigvitete med mitom, jezikom in glasbo.)

Iz obeh navedenih razlogov tako rekoč sili Brockmeierjevo vprašanje: "ali je spričo prepletenosti mita in umetnosti sploh mogoče govoriti o različnih obikah organizacije človekovega sveta in lastne izkušnje?" (Prav tam: 181.) Vprašanje je toliko bolj pomembno, saj to, "da se mit ne nanaša na nikakršne dejanskosti in da imena v njem ne označujejo nikakršnih realnih posameznikov, še ne pomeni, da se odpoveduje izkušenjski resničnosti," torej se ne odpoveduje ravno tisti razsežnosti, ki je ključna tudi za glasbo, namreč razsežnosti osebnega soočanja z ustvarjenim delom. Toda odgovor na zastavljeno vprašanje ne more biti pritrdilen, saj "tega razmerja ne kaže razumeti kot razmerja odslikave ali reference" (prav tam: 283). Nasprotno, kaže ga razumeti kot lastnost, ki jo je mogoče pripisati vrsti različnih pojavov, pomembnih predvsem zato, ker dopuščajo "vzpostaviti igro simbolnih zvez, ki zagotavlja relativno koherenco, stabilnost in trajnost celote" (prav tam: 190).

Lévi-Straussov pogled na razmerja med glasbo, jezikom in mitom torej odpre nekakšen "medprostor": točko, ki dopušča strukturno sorodnim (primerljivim) tvorbam dodajati, odvzemati ali spreminjati pomenski obseg. Osnovno vprašanje, ki se pri tem razkrije, se ne nanaša na smiselnost in metodološko problematičnost tovrstnega umevanja, temveč na namen: kaže iskati skupne poteze sicer različnih pojavov kot (1) osnovo za čim bolj podrobno povezovanje različnega ali kot (2) osnovo primerjanja različnega? Drugače zastavljeno vprašanje: kaže univerzalistične primerjave razumeti kot spoznavoslovno metodo, ki sodi na področje odkrivanja globljih procesov človekovega delovanja, ali so znanstvenopraktični pripomoček, ki odpira vprašanja interdisciplinarnosti in sodi na področje spoznavoslovnega inštrumentarija?

Zastavljenemu vprašanju, ki ne dopušča ostrega ločevanja med alternativama, je seveda mogoče očitati kratkovidnost. Vprašanji o spoznavoslovnem in znanstvenopraktičnem namenu univerzalističnega primerjanja glasbene in neglasbene oblikovnosti sta nedvomno med seboj dopolnjujoči se gledišči, ki se spuščata v širino prastare in v osnovi univerzalistične mišljenjske platforme o sredstvih in namenu. Toda ugovoru nemara umanjka prepričljivosti ob odgovoru, ki se vsiljuje v obliki še enega vprašanja, namreč: mar ni danes glavna težava $v$ tem, da na področju analize glasbe niso problematični novi znanstvenopraktični pripomočki (analitični inštrumentarij), temveč razslojenost prepričanj, katere globlje spoznavoslovne cilje kaže $\mathrm{z}$ analitičnim delom in inštrumentarijem doseči v obdobju, ko soobstaja množica primerljivih in če že ne enako tehtnih, vsaj primerljivo smiselnih ciljev?

\section{Slišano in predstavljeno IV: nameni ali namen razmejitve povezanega?}

Kot ena osrednjih zadreg sodobne muzikološke problematike se razkrivajo sicer smiselno zastavljene, ponekod upravičeno tudi polemično priostrene zahteve po upoštevanju različnih glasbenih zvrsti, žanrov, tradicij in kultur kot predmetov analize glasbe. To nikakor ni nov postulat, vendar je v zadnji četrtini 20. stoletja praktično veliko bolj dosledno upoštevana zahteva znotraj sicer k zahodnjaški glasbi orientirane evropske in ameriški muzikologije. Če to problematiko označimo kot vprašanje širše razumljenega središča in obrobja (Nettl 2000: 295), glasboslovne diskusije - se pravi: mimo vprašanj tipa pomembno/nepomembno, geografsko bližje/oddaljeno, v praksi prisotno/odrinjeno na obrobje zavesti današnjika ipd. - še posebej pogosto obkrožajo, prvič, ožji glasbe- 
no-analitični problem "žongliranja historizma in modernizma" (Dunsby 1992: 636) in, drugič, širši problemski sklop o upravičenosti in razlogih v praksi utečenega "striktnega etničnega zamejevanja" (prav tam).

Ožje vprašanje analize celotnega repertorija glasbe Zahoda je ozko povezano z vprašanjem analitičnega inštrumentarija, ki se je dodobra uveljavil znotraj muzikologije in se tu še vedno razvija. Nasprotno pa se zdi, da se analitični inštrumentarij za glasbo, ki se izmika umevanju po merilih koncepta glasbenega dela in ideala avtonomne glasbe, kljub nekaterim izjemno vrednim analitičnim metodam, šele poskuša uveljaviti. Vendar se zdi, da se kljub nekaterim obetavnim analitičnim nastavkom, ki skušajo povezati eggebrechtovske ravni analize $\mathrm{v}$ smeri razčlenjevanje glasbenega stavka ${ }^{\circledR}$ interpretacija izsledkov - na primer za področje resne glasbe J.-J. Nattiezova tripartitna analiza (Nattiez 1990) ali pa za etno glasbo "cantometrični" sistem A. Lomaxa (Lomax 1968) -, konsenz glede analitičnega inštrumentarija ne izmika zaradi različnih namenov analitičnega dela, temveč v prvi vrsti zaradi različno razumljene vloge analize glasbe v muzikologiji.

O tem nemara zgovorno priča dejstvo, da je v novi izdaji največje angleške glasbene enciklopedije The New Grove Dictionary of Music and Musicians kot zadnja postaja zgodovine analize glasbe - utemeljeno - postavljen analitični model Davida Lewina (Lewin 1985-6: 327-92). Ta prinaša $\mathrm{v}$ analizo "the use of Artificial Intelligence as a metaphor":

"p $=(E V$, CXT, P-R-LIST, ST-LIST)

Here the musical perception $\mathrm{p}$ is defined as a formal list containing four arguments. The argument EV specifies a sonic event or family of events being žperceived'. The argument CXT specifies a musical context in which the perception occurs. The argument P-R-LIST is a list of pairs $\left(\mathrm{p}_{\mathrm{i}}, \mathrm{r}_{\mathrm{i}}\right)$; each pair specifies a perception $\mathrm{p}_{\mathrm{i}}$ and a relation $r_{i}$ which $p_{i}$ bears to $p_{i}$. The argument ST-LIST is a list of statements $s_{1}, \ldots, s_{x}$ made in some stipulated language L."

Lewinov "provisional model" izhaja, simptomatično, s stališča recepcije. Sodi torej med deskriptivne analitične teorije, ki za razliko od preskriptivnih postopkov razčlenjevanja glasbenega stavka - torej tistih teorij glasbenega stavka, ki sistematično obravnavajo posamezno glasbeno prvino in se iztekajo v oblikoslovje - dopuščajo, da njihov jezik sestavljajo "poetične izjave ali zapise [...] freudovske svobodne asociacije [...] gestične 'trditve' iz drugih komunikacijskih sistemov, ki se ponavadi ne umeščajo v rubriko žjezik', geste kot so zapis izvirnega kompozicijskega gradiva, izvedba glasbenega odseka" (prav tam: 341) in podobna "nadjezikovna" izrazila. Lewinov analitični model torej s semantičnimi vzporednicami " $z$ različnih vetrov" odpira konceptom in terminologiji oblikovne analize pot, po kateri pojavnost glasbe zahteva interdisciplinarno obravnavo.

Njegov analitični pogled tako opozarja na dve med seboj dopolnjujoči se polji analitičnega dela, ki bi ju mogla nakazati razmejitev Lawrenca Zbikowskega med iskanji "hierarhije verige obstajajočega" ("chain-of-being hierarchy"), ki jo narekujejo analitične navade, in "atomistično hierarhijo" ("atomistic hierarchy") (Zbikowski 1997: 193-225), rezultat osrednje zahteve po "interdisciplinarnosti", h kateri v osnovi vodi "nezamejenost" zastavljanja vprašanj pri analizi, kot med drugimi poudarja $H$. H. Eggebrecht $v$ svojem četrtem priporočilu za analizo (Eggebrecht 1995: 135). Rešitev, meni Zbikowski, je v "integriranju teorij glasbe v širšo perspektivo kognitivne znanosti" (Zbikowski 1998: 218), kar bržkone zastavi več vprašanj, kot bi jih mogla odgovoriti. Število poddisciplin, ki bi ga morala najsi še tako različno razumljena kognitivna znanost vključevati v raziskavo, je resda mikaven in vsekakor tudi smiseln postulat. Vendar je obenem ta predlog vprašljiv, in to predvsem zaradi vsebinskega obsega pojma kognicije - lat. cognoscere: spoznati, spoznavno raziskovati - in veliko manj zaradi praktičnega "atomiziranja" obstoječih ana- 
litičnih pristopov, ki bi jim kognitivna znanost domnevno nadela uzde. Spričo razsrediščenosti muzikoloških hotenj, ki jo je Alastair Williams posrečeno imenoval "current hermeneutic turn" (Williams 2000: 403), namreč ni jasno, ali se s proklamacijo "postmodernistične odprtosti" problematizira množica različnega ali različnost interpretacij istega, kar nikakor ni enako.

\section{Razbrano}

Namenov analize $v$ nakazanem oziru ne kaže problematizirati ločeno od vprašanja od njihovih vlog znotraj širšega področja muzikologije. Še zlasti ne, ker je skupno potezo glasbenoanalitičnih prizadevanj "mogoče videti kot prispevek h konkretiziranju glasbenega dela s tem, da se posameznim sestavinam izdelka pripišejo učinki specifičnih [spoznavnih in ožje ali širše "kulturnih"] praks" ", kar je težko razumeti kot posledico "enostranskosti" posameznih analitičnih metod, saj je pogosto očitana "enostranskost" rezultat zahtev po "znanstvenosti" spoznavnega aparata. Spomniti kaže denimo na dejstvo, da se je jezik analize glasbe spreminjal počasneje od pomenskih polj, ki so se v različnih obdobjih širila okoli istega pojma (npr. pojem figure), in obrnjeno, da so posamezne morfološke kategorije dobivale različna imena, čeprav so se po svoji vlogi znotraj glasbene oblike nanašale na primerlije pojave (npr. subjekt/tema, odsek/perioda, člen/stavek).

Omenjeni Lewinov analitični model tako kaže razumeti kot željo po enovitosti analitične metodologije, podobno kot Lévi-Straussov univerzalistični enačaj med glasbo in drugimi pojavnimi oblikami človekovega duha: ne samo kot vpletanje novega "jezika", temveč tudi kot splet vprašanj o vrednostnih merilih, ki jih nakazujejo procesi intitucionaliziranja, ali rajši: imenovanja glasbenih oblik.

Procesi imenovanja glasbenih oblik, ki jih je mogoče razumeti kot vrsto iskanj "idealnega jezika o jeziku", je mogoče različno razumeti. Povezave $z$ gramatikalnimi in glasbeno-retoričnimi določili, ki so se prek "rhythmopoeie" J. Riepla (1752) in "periodologije" J. N. Forkla (1788) postopno spreminjale v "čisto glasbene", "formalistične" kategorije v oblikoslovju kot posebni glasbeno-teoretski disciplini pri A. B. Marxu v tridesetih letih 19. stoletja, so zgodovina glasboslovnega besedišča, ki ga je T. W. Adorno strnil kot "materielle Formenlehre der Musik" (pod tem nazivom je razumel skupek različnih splošno uveljavljenih oblikoslovnorecepcijskih pojmov \{ Adorno 1982: 185\}), V. Karbusicky (podobno Lévi-Straussu) kot "Urformen und Gestaltungskräfte" 10 ali pa P. Faltin kot "syntaktische Kategorien" (na primer: podobnost, kontrast, različnost ipd. \{ Faltin 1985: 114 in dalje; isti 1979 \} ).

Toda različnost umevanja in imenovanja oblikovnih značilnosti glasbenih tvorb kaže, da je soobstoj "stare" oblikoslovne terminologija v primerjavi z recimo konceptom "auditory stream segregations" A. Bregmana (Bregman 1992), ki prinaša pojmovne ustreznike za posamezne segmente oblikovnosti glasbenih pojavov s stališča kognitivne vede, privedel do točke, ko sta se "med seboj pomešali globina razlagalne teorije in globina estetskega izkustva." (Meyer 1998: 1, 13.) Analitik naj bi po eni strani tako rekoč izvajal vivisekcijo umetnine, ki živi kot del "estetskega kapitala" (N. Cook) znotraj kulture; ta pa po drugi strani zahteva od analitika - v kolikor naj ne ostane na ravni pedagoškega poenostavljanja in navade razumevanja glasbenega dela kot enkratne stvaritve,

\footnotetext{
${ }^{9}$ Horner (1998: 159-199) povzema razlike med izhodiščnimi pozicijami opazovanja v ameriški t. i. New musicology. Navedek, ki ga je mogoče razumeti tudi kot različico rdeče niti njegove študije o razlikah med posameznimi analiti nimi stališči, se v celoti glasi: "If Taruskin and McClary both can be seen as contributing to the reification of musical work by attributing to components of a product the effects of specific practices, other critics contribute equally to such reification by confusing inherent physical properties of the media of sound and sight with musical effects." (Horner 1998: 182.)

${ }^{10}$ Karbusicky (1991: 29 in dalje) izpeljuje svoj sistem glasbenih praoblik iz obrazca "Wiederholung + Variation", v katerem vidi "Urenergie der musikalischen Kreativität" (Karbusicky 1991: 38).
} 
katere sestavin ni smiselno navajati v slogu telefonskega imenika (C. Dahlhaus) - ravno nasprotno: jasno metodo, dodelane analitične postopke in nedvoumno terminologijo, ki bi omogočila primerljivost izsledkov na različnih ravneh ravno zato, ker bi morala spoznavna vrednost analiziranega temeljiti na logiki sistematizacije, ki je značilna (rečeno z Dahlhausovo ironično primerjavo) tudi za telefonski imenik.

V izogib morebitnemu očitku relativizacije - iz izvajanja bi namreč mogli domnevati, da gre za pledoaje analitičnega aparata, katerega osnovna naloga bi bila razkriti "cultural associations rather than purely intramusical dynamics" (Iyer 1998) - se kaže vrniti na Lévi-Straussov pogled. Treba je poudariti, da je treba iskati prednost njegovega univerzalističnega pogleda, značilnega tudi za najsi še tako različno razumljene "kognitivne analize" glasbenega stavka, iskari v odpiranju tistega ozkega šivankinega vratu, skozi katerega se glasbeni stavek kaže v podobi enega od jezikov. Lévi-Strauss torej odpira področje, v katerem glasba ni poseben jezik, ker ni običajnega jezika, jezika brez posebnosti. Vendar ravno s tem, ko jo "ozemlji" na raven množice jezikov, ki soobstajajo v določeni kulturi, omogoča izpostaviti tudi njene posebnosti.

\section{Literatura}

Theodor W. Adorno, 'On the Problem of Musical Analysis' (prev. Max Paddison), v: Music Analysis Vol. 1, No. 2, July 1982, 169-186.

Wallace Berry, Structural Functions in Music, Dover Publications, INC., New York ${ }^{2} 1987$.

Albert S. Bregman, Auditory Scene Analysis. The Perceptual Organisation of Sound, MIT Press, Massachusetts-Cambridge 1992.

Jens Brockmeier, 'Ordnung und Imagination. Formen und Funktionen des mythischen Denkens in der Kunst', v: Musik und Mythos. Neue Aspekte der Musikalischen Ästhetik, ur. Hans Werner Henze, Frankfurt am Main (Fischer Taschenbuch Verlag) 1999, 178234.

Bojan Bujiæ, 'Delicate metaphors, Bojan Bujic examines the relationship between music, conceptual thought and the New Musicology', v: The Musical Times 1997, June, 16-22.

Nicholas Cook, Music, Imagination \& Culture, Oxford University Press, Oxford 1992.

Nicholas Cook, A guide to Musical Analysis, Oxford University Press, Oxford 1994.

Carl Dahlhaus, 'Musikalische Logik und Sprachkarakter', v: Die Idee der absoluten Mu$s i k$, VEB Deutscher Verlag für Musik, Leipzig 1979, 105-117.

Jonathan Dunsby, 'Music Analysis: Commentaries', v: Companion to Contemporary Musical Thought, Vol. 2, Routledge (London and New York) 1992, 634-646.

Hans Heinrich Eggebrecht, Musik verstehen, Piper Verlag, München-Zürich 1995.

Peter Faltin, Phänomenologie der musikalischen Form (Beihefte zum AfMw Band XVIII), Wiesbaden 1979.

Peter Faltin, Bedeutung ästhetischer Zeichen, Musik und Sprache, ASSK Band 1, ur. Christa Nauck-Börner, Rader Verlag, Aachen 1985.

Bruce Horner, 'On the Study of Music as Material Social Practice', v: The Journal of Musicology, Volume XVI/2, Spring 1998, 159-199.

Kurt Hübner, Die zweite Schöpfung. Das Wirkliche in Kunst und Musik, C. H. Beck, München 1994.

Vijay S. Iyer, Implications for Music Cignition, Musicology, and Computer Music, v: Microstructures of Feel, Macrostructures of Sound: Embodied Cognition in West African and African-American Musics, U.C. Berkeley 1998, http://cnmat.cnmat.berkeley.edu/People/Vijay/08.\%20Conclusions.html 
Vladimir Karbusicky, 'Musikalische Urformen und Gestaltungskräfte', v: Otto Kolleritsch, ur., Musikalische Gestaltung im Spannungsfeld von Chaos und Ordnung, Studien zur Wertungsforschung, Band 23, Wien - Graz, 29-85.

Joseph Kerman, 'How We Got into Analysis, and How to Get Out', Critical Inquiry, Winter 1980, 311-331.

Heinrich Christoph Koch, Versuch einer Anleitung zur Composition I, Rodolstadt/Leipzig 1782. Nav. po faksimilu izvirnika Georg Olms Verlag, Hildesheim 1969.

Clemens Kühn, Formenlehre der Musik, Bärenreiter, DTV, ${ }^{3} 1992$.

Jan LaRue, Guidelines for Style Analysis, Harmonie Park Press, Michigan ${ }^{2} 1992$.

Fred Lerdahl / Ray Jackendoff, A Generative Theory of Tonal Music, MIT Press, Cambridge 1983.

Claude Lévi-Strauss, 'Musik und Mythos', v: Mythos und Bedeutung, Bibliothek Suhrkamp 1995, 65-79.

David Lewin, Music Theory, 'Phenomenology, and Modes of Perception', v: Music Perception, iii (1985-6), 327-92.

Alan Lomax, Folk Song Style and Culture, American Association for the Advancement of Science, Washington 1968.

Leonard B. Meyer, 'A Universal of Universals', v: The Journal of Musicology XVI, 1998, Number 1, 3-25.

Jean-Jacques Nattiez, Music and Discours. Toward a Semiology of Music, Princeton University Press, New Jersey.Oxford 1990.

Bruno Nettl, 'The Institutionalization of Musicology: Perspectives of a North American Ethnomusicologist'; v: Rethinking Music, ur. Nicholas Cook in Mark Everist, Oxford University Press, Oxford, 287-310.

Antonin Reicha (prev. Carla Czernyja), Vollständiges Lehrbuch der musikalischen Composition IV, Dunaj 1834.

Joseph Riepel, De rhythmopoeia oder von der Tactordnung, 1752. Grundregeln zur Tonordnung insgemein, 1755. Nav po Joseph Riepel, Sämtliche Schriften zur Musiktheorie, ur. Thomas Emmerig, Böhlau Verlag Wien/Köln/Weimar.

Adolf Bernhard Marx, Die Lehre von der musikalischen Komposition praktisch-theoretisch I, 1837. Nav. po redakciji Huga Riemanna, Leipzig ${ }^{9} 1887$. Die Lehre von der musikalischen Komposition praktisch-theoretisch II, 1838. Nav. po redakciji Huga Riemanna, Leipzig 71890.

Jim Samson, 'Analysis in Context', v: Rethinking Music, ur. Nicholas Cook in Mark Everist, Oxford University Press, Oxford 22001, 35-54.

Lothar Schmidt, Organische Form in der Musik. Stationen eines Begriffs 1795-1850, Bärenreiter, Kassel/Basel/London/New York 1990.

Ulrich Tadday, Das schöne Unendliche. Ästhetik, Kritik, Geschichte der romantischen Musikanschauung, J. B. Metzler Verlag, Stuttgart-Weimar 1999.

Lotte Thaler, Organische Form in der Musiktheorie des 19. und beginnenden 20. Jahrhunderts, Berliner musikwissenschaftliche Arbeiten, ur. Carl Dahlhaus in Rudolf Stephan, Band 25, Musikverlag Emil Katzbichler, München/Salzburg 1984.

Alastair Williams, 'Musicology and Postmodernism', v: Music Analysis, Volume 19, No. 3 , October 2000, 183-192.

Lowrence Zbikowski, 'Conceptual Models and Cross-Domain Mapping: New Perspectivec on Theories of Music and Hierarchy', v: Journal of Music Theory, Fall 1997, Volume 41, Number 2, 193-225. 